\title{
Generating p53-specific cytotoxic T lymphocytes by recombinant adenoviral vector-based vaccination in mice, but not man
}

\author{
J Kuball ${ }^{1}$, M Schuler ${ }^{1}$, E Antunes Ferreira ${ }^{1}$, W Herr ${ }^{1}$, M Neumann ${ }^{2}$, L Obenauer-Kutner ${ }^{2}$, \\ L Westreich $^{2}, \mathrm{C} \mathrm{Huber}^{1}$, T Wölfel ${ }^{1}$ and M Theobald ${ }^{1}$ \\ ${ }^{1}$ Department of Hematology and Oncology, Johannes Gutenberg-University, Mainz, Germany; and ${ }^{2}$ Schering-Plough Research \\ Institute, Kenilworth, NJ, USA
}

\begin{abstract}
Mutations and aberrant expression of the p53 tumor suppressor protein are the most frequent molecular alterations in human malignancy. Peptides derived from the wild-type (wt) p53 protein and presented by major histocompatibility complex (MHC) molecules for $T$ lymphocyte recognition are believed to serve as universal tumor-associated antigens for cancer immunotherapy. We studied the immunogeneicity of a recombinant replication-defective adenoviral vector encoding human full-length wt p53 (rAd/hup53) in human leukocyte antigen (HLA)-A2K $K^{b}$-transgenic ( $T g$ ) mice and man. The generation of p53 epitope-specific cytotoxic $T$ lymphocytes (CTLs) in p53-proficient and p53-deficient A2K ${ }^{b}-\mathrm{Tg}$ mice was affected by self-tolerance and a selective inability of rAd/hup53 to induce p53.264-272 peptide-reactive effector
\end{abstract}

Keywords: adenovirus; CTL; p53; tolerance; pilot study

\section{Introduction}

Functional inactivation of the p53 tumor suppressor protein occurs in the majority of human (hu) cancers and is predominantly caused by mutational alteration of the wt p53 sequence. ${ }^{1}$ Accumulation and subsequent overexpression of altered p53 protein is associated with highlevel presentation of p53-derived peptides by MHC class I molecules on malignant cells. ${ }^{2-11}$ Due to the diversity of p53 mutations in different tumors, peptides representative of $w \mathrm{t}$, as opposed to mutant p53 sequences, were proposed to serve as universal tumor associated antigens (Ags) for a CTL-based immunotherapy of cancer. ${ }^{2-11}$ Increased susceptibility of malignant cells to lysis by wt p53-specific CTLs has been demonstrated more recently to be linked rather to a high turnover rate than to a high steady-state level of p53 protein expression. ${ }^{12}$ A major barrier to the design of broad-spectrum p53-specific immunotherapeutics, however, has been the observation that low-level expression of wt p53 peptides by nontransformed tissues and cells results in self-tolerance of

Correspondence: $M$ Theobald, Department of Hematology and Oncology, Johannes Gutenberg-University, Langenbeckstr 1, 55101 Mainz, Germany

$M$ Schuler and E Antunes Ferreira contributed equally to this work Received 2 November 2001; accepted 22 February 2002 cells. To extend this study into a pilot clinical trial, six advanced-stage cancer patients received sequential injections of rAd/hup53. The treatment was well tolerated. To date, no evidence for objective tumor responses was observed. An amplification of humoral and cellular anti-adenoviral immune responses was demonstrated in all patients following $r A d / h u p 53$ vaccination. However, p53-reactive antibodies and HLA-A*0201 (A2.1)-restricted CTLs specific for wt p53 epitopes were not generated. Tailoring p53-based cancer immunotherapy thus requires the interference with p53-specific self-tolerance and the induction of the entire repertoire of p53-reactive $T$ lymphocytes.

Gene Therapy (2002) 9, 833-843. doi:10.1038/sj.gt.3301709

T lymphocytes with high avidity for self-MHC class I/self-p53-peptide complexes. ${ }^{6,7}$ Although the peripheral $\mathrm{T}$ cell repertoire is mostly devoid of such high-avidity wt p53 epitope-specific CTLs due to self-tolerance, this does not necessarily preclude the possibility of developing wt p53-directed vaccination strategies for cancer patients. Low-avidity and even residual high-avidity CTLs have been demonstrated to partially escape the induction of $\mathrm{wt}$ p53-specific self-tolerance. . $^{3,9,11,13}$ In some studies, such CTLs have been reported to be able to lyse p53-overexpressing tumor cells in vitro and to protect mice vaccinated with peptide-pulsed dendritic cells (DCs) from tumor growth. ${ }^{3-7,9,11}$ However, to obtain these CTLs in man, extensive in vitro selection was required, consistent with a low precursor frequency of such $\mathrm{T}$ lymphocytes within the peripheral hu $\mathrm{T}$ cell repertoire. $5,11,13$

Several vaccination strategies have been successfully employed in mice in order to prime murine (mu) and hu wt p53 epitope-specific CTLs. These attempts included peptide immunization along with an adjuvant, ${ }^{2,6,8}$ inoculation of recombinant vaccinia virus containing minigenes that encoded for hu wt p53 epitopes downstream of an endoplasmic reticulum insertion sequence, ${ }^{10}$ canarypox viral recombinants expressing hu or $\mathrm{mu}$ wt p53 protein, ${ }^{4}$ and transfer of DCs pulsed with mu wt p53 peptides ${ }^{3}$ or transduced with a recombinant adenoviral vector encoding hu wt p53. ${ }^{14}$ 
These studies left unresolved the issue whether lowavidity and residual high-avidity CTLs specific for wt p53 peptide epitopes could be primed and amplified in man. We therefore studied the ability of a recombinant replication-defective adenoviral vector encoding full length hu wt p53, rAd/hup53, to induce p53-specific

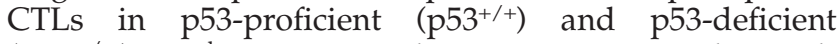
$\left(\mathrm{p} 53^{-/-}\right.$) A2 $\mathrm{K}^{\mathrm{b}}-\mathrm{Tg}$ mice, and in A2.1-positive, advancedstage cancer patients.

\section{Results}

\section{A2.1-restricted and p53-specific CTL responses are elicited by $\mathrm{rAd} / \mathrm{hup53}$ in Tg mice and affected by self- tolerance}

To investigate the efficiency of p53-specific CTL induction by $\mathrm{rAd} / \mathrm{hup} 53$, $\mathrm{p} 53^{-/-}$and $\mathrm{p} 53^{+/+} \mathrm{A} 2 \mathrm{~K}^{\mathrm{b}}-\mathrm{Tg}$ mice were challenged with $\mathrm{rAd} /$ hup53 or the empty adenoviral vector (rAd/empty). Spleen cells were restimulated with p53 peptide-pulsed syngeneic Ag-presenting cells (APCs), and the resultant bulk-derived effector cells were tested for their A2.1-restricted and p53 epitope-specific cytolytic activity. Only those p53 peptides that had been proven to function as naturally processed A2.1 ligands were selected. Peptides were either homologous (p53.187197 and 322-330) or non-homologous (p53.149-157 and 264-272) to $\mathrm{mu}$ self-p53 sequences. Equivalent CTL responses specific for the non-homologous p53.149-157 epitope were demonstrated with responder spleen cells obtained from both, rAd/hup53 immunized p53-/- and $\mathrm{p} 53^{+/+}$A2K $\mathrm{K}^{\mathrm{b}} \mathrm{Tg}$ mice (Figure 1a). A2.1-restricted CTLs responding to the homologous p53.187-197 epitope were induced only in $\mathrm{p}^{2} 3^{-/-}$, but not in $\mathrm{p}^{53^{+/+}} \mathrm{A} 2 \mathrm{~K}^{\mathrm{b}}$-transgenics after priming with rAd/hup53 (Figure 1b). The peptide specificity and A2.1-restriction of responding CTLs were ascertained by their failure to lyse $\mathrm{T} 2 \mathrm{~A} 2 \mathrm{~K}^{\mathrm{b}}$ cells coated with an unrelated A2.1-binding peptide (FluM1 58-66), and lack of recognition of A2.1-negative EL4 targets pulsed with the stimulatory p53 peptide (Figure 1a and b). Effector CTLs specific for p53.149-157 and p53.187-197 were of sufficiently high avidity (Figure 1d and e) to selectively respond to Saos-2/143 p53-transfectants (Figure 2a and b). The amount of Saos-2/143 lysis observed for these bulk-derived effector cells was low, as CTLs from an $\mathrm{A} 2 \mathrm{~K}^{\mathrm{b}}-\mathrm{Tg}$ background are usually at a disadvantage in recognizing hu targets that express A2.1 as opposed to chimeric $\mathrm{A} 2 \mathrm{~K}^{\mathrm{b}} \cdot{ }^{15,16}$ CTLs specific for p53.149-157 and 187-197 were only generated after in vivo priming with rAd/hup53 as opposed to rAd/empty (data not shown). This indicates that these p53 peptides were endogenously processed and presented by rAd/hup53 infected mu APCs in vivo, and precludes the possibility of a primary in vitro induction of effector cells by peptide-pulsed stimulator cells. Although the homologous peptide p53.322-330 represents a naturally processed ligand for A2.1-molecules, ${ }^{17}$ epitope-specific CTL responses could not be demonstrated in either strain of Tg mice (data not shown), consistent with previous observations. $^{6}$

The immunogeneicity of rAd/hup53 in vivo is affected by its selective inability to generate A2.1-restricted CTLS specific for the hu wt p53.264-272 epitope

In contrast to vaccination with peptide or recombinant vaccinia viral minigene constructs,,$^{2,6,10}$ delivery of
$\mathrm{rAd} /$ hup53 in either strain of $\mathrm{Tg}$ mice failed to prime CTLs in response to the non-homologous p53.264-272 peptide (Figures 1c, $\mathrm{f}$ and 2c). This selective lack by rAd/hup53 in generating p53.264-272 epitope-specific CTLs was also observed following simultaneous restimulation of spleen cell aliquots from $\mathrm{rAd} /$ hup53 vaccinated p53 $3^{-/-}$and $\mathrm{p} 53^{+/+} \mathrm{A} 2 \mathrm{~K}^{\mathrm{b}}-\mathrm{Tg}$ animals with peptides p53.149-157, 187-197, and 264-272 (Figures 1a, c, d, f, 2a, c and data not shown). Boost injections of rAd/hup53 into either line of mice did not modify the inability of the vector to recruit p53.264-272 reactive effector cells (data not shown). The failure to induce p53.264-272 epitopespecific CTLs in vivo was only observed after delivery of $\mathrm{rAd} /$ hup53. In contrast, an induction of A2.1-restricted effector $\mathrm{T}$ cells responding simultaneously to all of the potentially immunogeneic wt p53 CTL epitopes was found following triple-peptide vaccination (data not shown).

The p53.264-272 CTL epitope was processed and presented by $\mathrm{rAd} /$ hup53 infected APCs. A2.1-positive DCs transduced with $\mathrm{rAd} /$ hup53 were efficiently recognized by A2.1-restricted CTLs specific for p53.187-197 and 264-272, whereas rAd/empty or non-infected DC targets were killed only by non-peptide-dependent and alloA2.1-reactive CTLs (Figure 3). Infected and non-infected DCs were resistant to lysis by A2.1-restricted and FluM1 58-66 peptide-reactive CTLs.

These findings indicate that $\mathrm{rAd} /$ hup53 is capable of priming A2.1-restricted and hu wt p53 epitope-specific CTLs in vivo. Its immunogeneic efficiency, however, is affected by p53-specific self-tolerance. The results also demonstrate a selective inability of $\mathrm{rAd} /$ hup53 to recruit CTLs specific for p53.264-272.

\section{Immunizing advanced cancer patients with rAd/hup53: clinical responses and side-effects}

To study the ability of rAd/hup53 to induce low-avidity and residual high-avidity p53-specific CTLs in man, A2.1positive advanced-stage cancer patients were enrolled in a clinical trial to receive $\mathrm{rAd} /$ hup53. The base line characteristics of six patients enrolled in the study and the sideeffects observed after the first and second rAd/hup53 vaccination are summarized in Table 1. As of July 2001, no objective tumor responses were observed. Transient local erythema at the injection site was common in all patients and occurred after each immunization. Systemic side-effects were limited to fever (WHO grade 1) and mild chills on the days of vaccination. No additional treatment-related adverse events were recorded during and after vaccination with $\mathrm{rAd} /$ hup53.

\section{Adenovirus and p53-specific antibody $(A b)$ responses}

Titers of pre-immunization anti-adenoviral Abs, including neutralizing Abs, were detected in the sera of all patients (Figure 4). An increment of Ab titers was demonstrated in all patients at 4 to 14 days after the first vaccination. Neutralizing anti-adenoviral Abs were further amplified after the second $\mathrm{rAd} /$ hup53 treatment in one of six patients. Anti-p53-specific Abs were not detected (data not shown).

\section{Anti-adenoviral Abs do not prevent the induction of adenoviral backbone-reactive $T$ lymphocytes}

A prerequisite for an efficient vaccination strategy in cancer patients is its ability to induce or amplify tumor- 

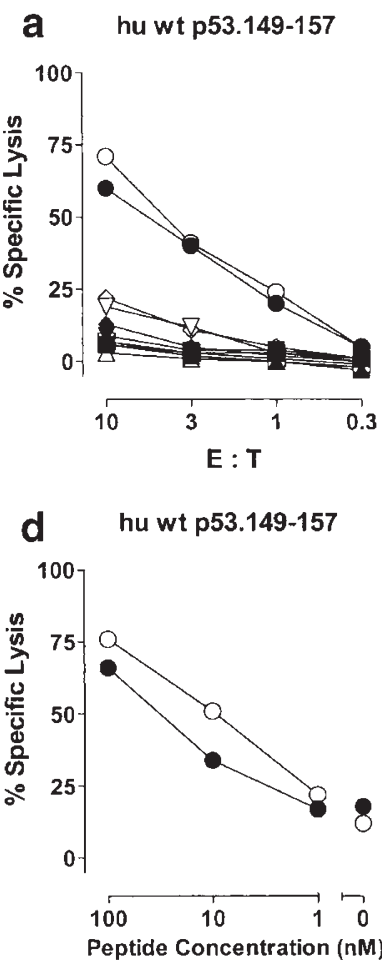

b wt p53.187-197
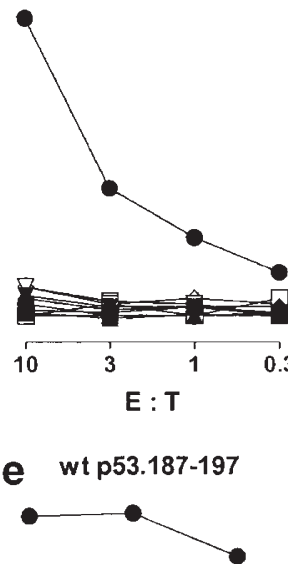

C hu wt p53.264-272

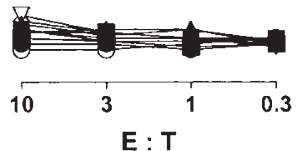

f hu wt p53.264-272

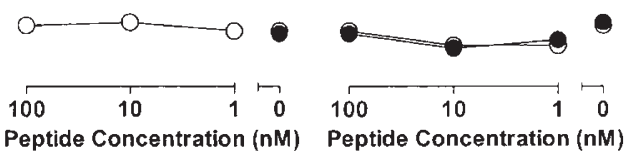

Figure 1 Induction of A2.1-restricted and wt p53 epitope-specific CTLs by rAd/hup53 delivery into $p 53^{-1-}$ and p53 ${ }^{+/+}$A2 $\mathrm{K}^{b}-\mathrm{Tg}$ mice. Mice were immunized i.p. with rAd/hup53. Spleen cells derived after 3 weeks from $p 53^{-I_{-}}(\mathbf{\bullet}, \mathbf{\Lambda}, \mathbf{\square}, \boldsymbol{\nabla}, \diamond)$ and $p 53^{+/+}(\bigcirc, \triangle, \square, \nabla, \diamond)$ A2 $\mathrm{K}^{b}-\mathrm{Tg}$ animals were restimulated for 6 days with syngeneic LPS blasts pulsed with the indicated p53 peptides. Effector CTLs were tested at the indicated E:T ratios in a 5-h ${ }^{51} \mathrm{Cr}$ release assay for recognition of $T 2 A 2 K^{b}$ targets $(a-c)$ pulsed with the indicated primary stimulating p53 peptide at 10-6 M (๑,O), the FluM1 58-66 peptide at $10^{-5} \mathrm{M}(\boldsymbol{\Delta}, \triangle)$, or no peptide $(\boldsymbol{\square}, \square)$, and non-peptide-pulsed EL4 targets $(\boldsymbol{\nabla}, \nabla)$ or the same cells pulsed with the indicated primary stimulating p53 peptide at $10^{-6} M(\diamond, \diamond)$. The efficiency of p53 peptide recognition by the indicated effector CTLs is presented at E:T ratios of 30:1 (d-f). The results shown are representative of four independent experiments and at least seven mice per strain and peptide.

a hu wt p53.149-157

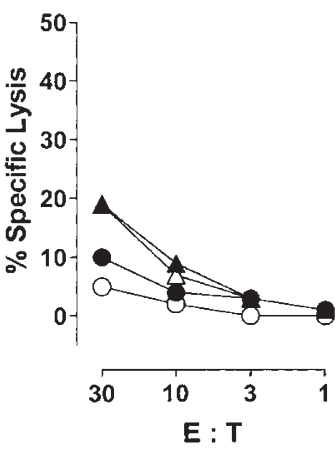

b wt p53.187-197

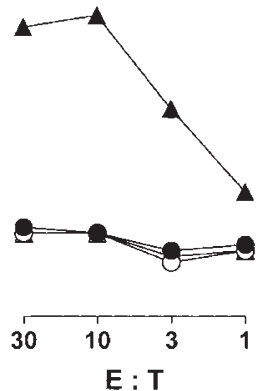

C hu wt p53.264-272

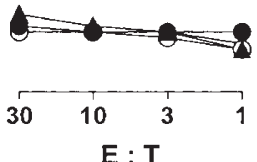

Figure 2 A2.1-restricted effector CTLs derived from rAd/hup53 vaccinated $p 53^{-/-}$and $p 53^{+/+} A 2 K^{b}-T g$ mice and specific for p53.149-157 and 187-197 are of sufficiently high avidity to recognize naturally processed CTL epitopes. Mice were immunized i.p. with rAd/hup53. Spleen cells derived after 3 weeks from $p 53^{-/-}(\mathbf{O}, \mathbf{\Delta})$ and $p 53^{+/+}(O, \triangle) A 2 K^{b}-T g$ animals were restimulated for 6 days with syngeneic LPS blasts pulsed with the indicated p53 peptides. Effector CTLs were tested at the indicated E:T ratios in a $5-h{ }^{51} \mathrm{Cr}$-release assay for recognition of p53-deficient Saos-2 targets $(\mathbf{O}, \mathrm{O})$ and the same cells transfected with hu mutant p53, Saos-2/143 $(\boldsymbol{\Delta}, \triangle)$. The results shown are representative of four independent experiments and at least seven mice per strain and peptide.

reactive cellular immune responses. To evaluate whether cellular immune responses were generated by sequential rAd/hup53 immunization or were compromised by adenovirus-specific Abs, we studied pre- and post-vaccination frequencies of peripheral interferon- $\gamma$ (IFN- $\gamma$ ) secreting $\mathrm{CD}^{+}$and $\mathrm{CD}^{+} \mathrm{T}$ lymphocytes in response to adenovirus-infected autologous DCs (Figure 5). A substantial number of pre-existing IFN- $\gamma$-secreting and aden- oviral backbone-reactive $\mathrm{CD}^{+} \mathrm{T}$ cells were observed in at least one patient (001). An increase of post-vaccination adenovirus-responsive $\mathrm{CD}^{+} \mathrm{T}$ lymphocyte frequencies could be demonstrated in all patients, albeit to a variable extent. Although the individual kinetics of inducing backbone-reactive $\mathrm{CD}^{+} \mathrm{T}$ cells by $\mathrm{rAd} /$ hup53 delivery varied considerably, responsive $\mathrm{T}$ lymphocytes were commonly detected as late as 7 weeks after the second 


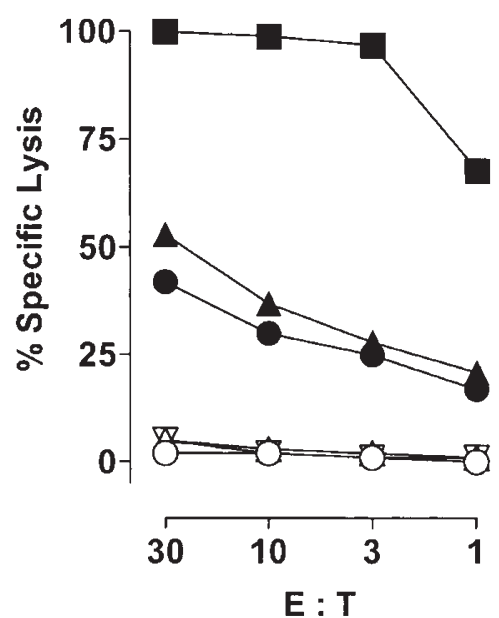

CTLCD8 x A2K ${ }^{b}$ FluM1

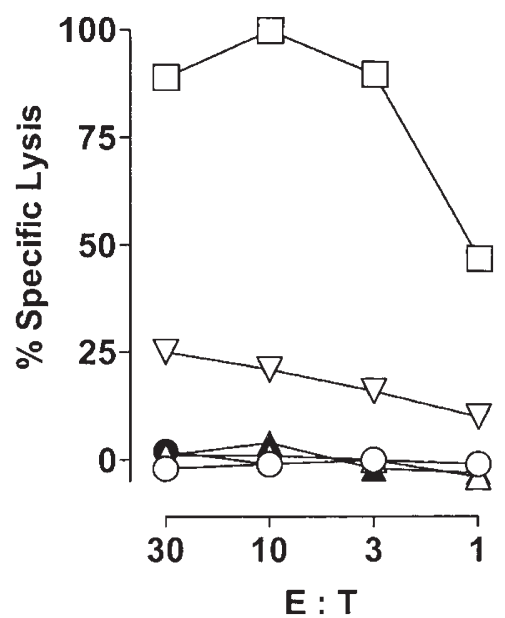

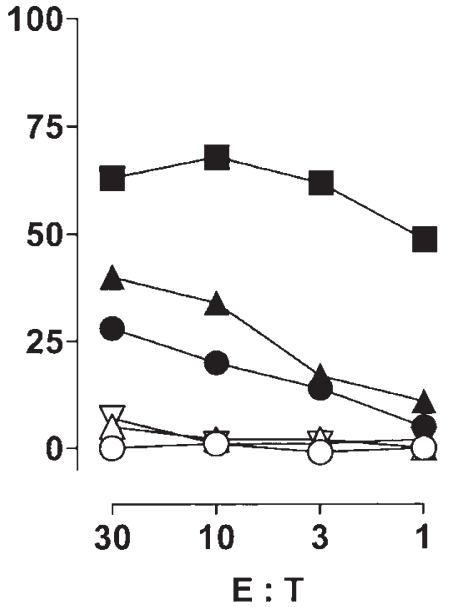

CTL CD8 Allo A2

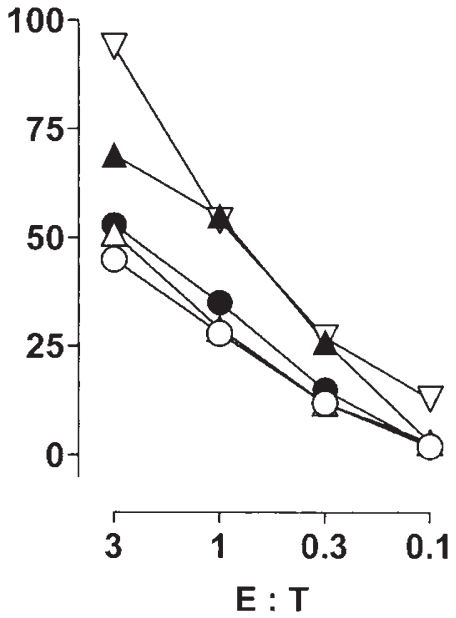

Figure 3 The p53.264-272 epitope is presented by rAd/hup53 infected DCs at copy numbers that are sufficient to trigger high-avidity effector CTLs. A2.1-positive mature DCs (O) were infected with either rAd/hup53 at MOIs of $100(\mathbf{O})$ and $300(\mathbf{\Delta})$ or rAd/empty at a MOI of $300(\triangle)$. Infected and non-infected DCs, as well as T2 cells that had been pulsed with either the stimulatory p53 peptide at $10^{-6} M(\mathbf{\square})$, the FluM1 58-66 peptide at $10^{-5} \mathrm{M}(\square)$, or no peptide $(\nabla)$, served as targets at the indicated E:T ratios in a $5-h{ }^{51} \mathrm{Cr}$-release assay. A2.1-restricted effector cells were a CTL clone specific for p53.264-272 (CTL A2 $264 \mathrm{cl} 46)$, a p53 ${ }^{-1-}$ A2K $\mathrm{K}^{b}$-Tg mouse-derived CTL line specific for p53.187-197 (CTL A2Kb 187), a CTL line specific for FluM1 58-66 (CTL CD8 $\times A 2 K^{b}$ FluM1), and an allo-A2.1-reactive CTL line (CTL CD8 Allo A2).

vaccination. Adenoviral backbone-reactive and IFN- $\gamma$ producing $\mathrm{CD}^{+} \mathrm{T}$ lymphocytes were absent from prevaccination peripheral blood mononuclear cells (PBMCs) of all patients (Figure 5). However, significant numbers of these effector $\mathrm{T}$ cells were recruited after exposure to rAd/hup53 and persisted up to 7 weeks following the second vaccination (patients 001 and 004). In the remaining patients, adenovirus-responsive and IFN- $\gamma$-secreting $\mathrm{CD}^{+} \mathrm{T}$ lymphocytes did not develop, even after the second vaccination. Frequencies of Epstein-Barr virus (EBV)-reactive $\mathrm{CD}^{+} \mathrm{T}$ cells remained stable over time in all except one evaluable patient (data not shown).

Based on these results, we conclude that vaccinated patients were not affected by an overall immunosuppression or T cell anergy in the background of advanced cancer. These observations also indicate that Ag-reactive and functional $\mathrm{T}$ lymphocyte responses, even in elderly patients with advanced-stage malignancies, can be induced and amplified by rAd/hup53 vaccination and are not necessarily limited by anti-adenoviral Abs. As expected with adenoviral vectors, ${ }^{18}$ peripheral backbonereactive $\mathrm{T}$ cell responses appeared to be skewed predominantly towards the $\mathrm{CD}^{+} \mathrm{T}$ cell subset.

\section{Functional T lymphocytes specific for p53 are not recruited by vaccination of cancer patients with rAd/hup53}

To evaluate whether low-avidity and residual high-avidity CTLs specific for self-p53 could be primed and expanded by rAd/hup53 delivery, pre- and post-vaccination frequencies of A2.1-restricted and hu wt p53 peptide-specific IFN- $\gamma$-producers within peripheral blood- 
Table 1 Patient characteristics $(n=6)$

\begin{tabular}{|c|c|}
\hline \multicolumn{2}{|l|}{ Age (years) } \\
\hline Range & $53-76$ \\
\hline Medium & 66 \\
\hline \multicolumn{2}{|l|}{$\operatorname{Sex}(n)$} \\
\hline Male & 4 \\
\hline Female & 2 \\
\hline \multicolumn{2}{|l|}{ Maligancy $(n)$} \\
\hline Urogenital cancer & 3 \\
\hline Lung cancer & 2 \\
\hline Malignant Schwannoma & 1 \\
\hline \multicolumn{2}{|c|}{ Side-effects of rAD/hup53 delivery ${ }^{\mathrm{a}}(n)$} \\
\hline \multicolumn{2}{|l|}{ After first injection } \\
\hline Local erythema grade 1 & 6 \\
\hline Mild chills & 2 \\
\hline Fever grade 1 & 1 \\
\hline \multicolumn{2}{|l|}{ After second injection } \\
\hline Local erythema grade 1 & 6 \\
\hline Fever grade 1 & 1 \\
\hline \multicolumn{2}{|l|}{ Clinical responses $(n)$} \\
\hline \multicolumn{2}{|l|}{ End of study (3 months) } \\
\hline Stable disease & $\begin{array}{l}2\left(\mathrm{p} 53^{+} \text {tumor }\right)^{\mathrm{b}} \\
2\left(\mathrm{p} 53^{-} \text {tumor }\right)\end{array}$ \\
\hline Progressive disease & 1 (p53+ tumor) \\
\hline & 1 (p53- tumor) \\
\hline $\begin{array}{l}\text { Follow-up (7-16 months) } \\
\text { Stable disease }\end{array}$ & Follow-up (7-16 months) \\
\hline Progressive disease & 5 \\
\hline
\end{tabular}

aSide-effects were graded according to the WHO recommendations for acute and subacute toxicities. ${ }^{53}$

${ }^{\mathrm{b}}$ As determined by immunohistochemistry.

cAt a follow-up period of 11 months.

derived $\mathrm{CD}^{+} \mathrm{T}$ lymphocytes were studied. For this purpose, we took advantage of hu wt p53 peptides that were endogenously processed and bound by A2.1 (p53.322$330),{ }^{17}$ and those representing natural epitopes recognized by tumor-reactive CTLs on p53-overexpressing malignant cells (p53.149-157, 187-197 and 264-272). However, A2.1-restricted and IFN- $\gamma$-spot-forming CD8 ${ }^{+} \mathrm{T}$ cells responding to either p53 peptide as opposed to an EBVderived control peptide (EBV-B 280-288) were not detected in the study patients before and after vaccination (data not shown).

By comparing pre- and post-vaccination frequencies of IFN- $\gamma$-secreting $\mathrm{T}$ cell subsets stimulated with rAd/hup53 or rAd/empty infected autologous DCs, we also failed to observe p53-specific $\mathrm{CD}^{+}$or $\mathrm{CD}^{+} \mathrm{T}$ lymphocyte responses. Stimulation of $\mathrm{CD}^{+}$and $\mathrm{CD}^{+} \mathrm{T}$ cells with autologous DCs pulsed with p53 or human papilloma virus E7 protein confirmed the absence of p53-specific IFN- $\gamma$-producers in patient 001 pre- and post-vaccination (data not shown).

\section{Discussion}

We studied the ability of rAd/hup53 to induce wt p53specific immune responses in $\mathrm{A} 2 \mathrm{~K}^{\mathrm{b}}-\mathrm{Tg}$ mice and advanced-stage cancer patients. We found that transfer of $\mathrm{rAd} /$ hup53 into $\mathrm{Tg}$ mice was able to prime A2.1restricted and p53-specific CTLs. However, the comparison of p53 epitope-reactive CTL responses in $\mathrm{p} 53^{-/-}$and $\mathrm{p} 53^{+/+} \mathrm{Tg}$ animals revealed that $\mathrm{p} 53$-specific self-tolerance is not affected by $\mathrm{rAd} /$ hup53 vaccination.

It has been demonstrated that low-avidity $\mathrm{T}$ cells can escape the induction of self-tolerance, emerge into the periphery, and survive. ${ }^{19}$ This has also been shown for epitopes. ${ }^{5,6,9,11,13,20}$ Consistent with these observations, the delivery of a recombinant canarypox virus expressing mu wt p53 protected mice against subsequent tumor cell challenge. ${ }^{4}$ We could not detect A2.1-restricted CTLs with low avidity for the homologous p53.187-197 epitope in

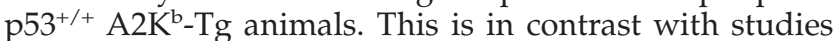
employing hu PBMCs to induce low-avidity CTLs specific for the p53.187-197 peptide in vitro. ${ }^{20}$ The potential reasons for this discrepancy have been discussed previously. 6

Immunization of $\mathrm{p} 53^{-/-}$and $\mathrm{p} 53^{+/+} \mathrm{A} 2 \mathrm{~K}^{\mathrm{b}}-\mathrm{Tg}$ mice revealed a selective inability of $\mathrm{rAd} /$ hup 53 to promote CTLs responding to the wt p53.264-272 peptide in the absence of an operational p53-specific self-tolerance. Although p53.264-272 has been shown to represent a subdominant proteasomal degradation product, ${ }^{10}$ this CTL epitope was processed and presented by $\mathrm{rAd} / \mathrm{hup} 53$ infected APCs at a level that allowed efficient recognition by high-avidity effector CTLs. Considering that a higher amount of $\mathrm{Ag}$ is required to activate naive versus effector and low- versus high-avidity $\mathrm{T}$ lymphocytes, ${ }^{21,22}$ it is likely that the level of p53.264-272 peptide presentation by rAd/hup53 infected APCs in vivo was inadequate for the induction of naive $\mathrm{T}$ cells and may have also been affected by immunodominance of other p53- and adenovirus-derived CTL epitopes. ${ }^{23}$ The possibility that the hu p53.264-272 Ag (LLGRNSFEV) had become deaminated in mu APCs resulting in the presentation of a peptide homologous to the A2.1-presented mu p53.261-269 CTL epitope (LLGRDSFEV) ${ }^{6}$ was excluded by restimulating spleen cells from p53-deficient and proficient $\mathrm{A} 2 \mathrm{~K}^{\mathrm{b}}-\mathrm{Tg}$ animals with mu p53.261-269 peptide-pulsed stimulators. In contrast to peptide immunization, ${ }^{6}$ we did not find CTL responses specific for the deaminated $\mathrm{mu} A g$ (data not shown).

Based on observations that the human $\mathrm{T}$ cell repertoire is not necessarily devoid of low- and even residual highavidity p53-specific CTLs, $5,9,11,13,20$ we investigated rAd/hup53-specific immune responses by sequential vaccination of A2.1-positive, advanced-stage cancer patients. The treatment was well tolerated, but no apparent tumor responses were demonstrated in the study cohort. Along with previous reports, ${ }^{24,25}$ we observed humoral anti-adenoviral immune responses which were further amplified by the study treatment. The induction of adenoviral backbone-reactive and IFN- $\gamma$-producing $\mathrm{CD}^{+}$and $\mathrm{CD}^{+} \mathrm{T}$ lymphocytes in $\mathrm{rAd} /$ hup53-immunized cancer patients, however, was not prevented by adenovirus-specific neutralizing Abs. As the vector used in our trial was replication-defective, these findings are consistent with studies in mice that report the induction of an adenovirus-directed cellular immune response in the absence of viral gene expression. ${ }^{26}$ Adenovirusreactive $\mathrm{T}$ lymphocyte responses and the detection of EBV epitope-specific $\mathrm{CD}^{+}$effector $\mathrm{T}$ cells before and after vaccination demonstrated that the study patients were not necessarily prone to immunosuppression or $\mathrm{T}$ cell anergy by their advanced-stage cancer.

While p53-specific Abs are known to occur in patients with malignant disease harboring a mutational p53 protein, ${ }^{27}$ we were unable to demonstrate p53-directed humoral immune responses in our study patients. Antip53 Abs even remained absent following rAd/hup53 vac- 
Patient 001

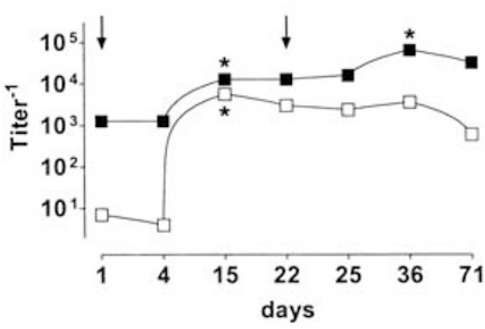

Patient 003

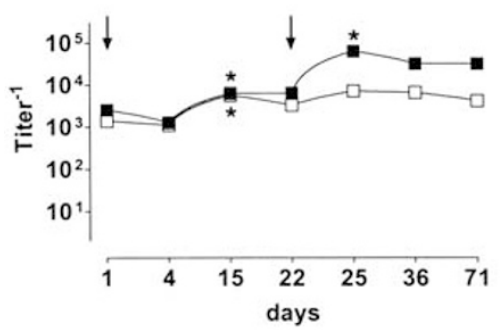

Patient 005

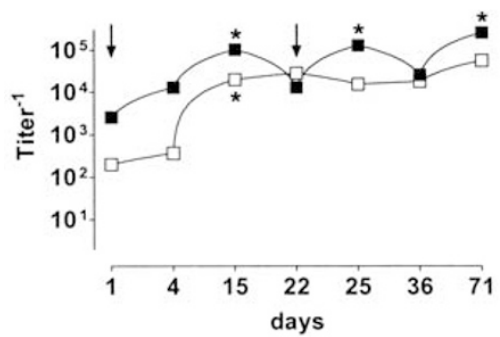

Patient 002

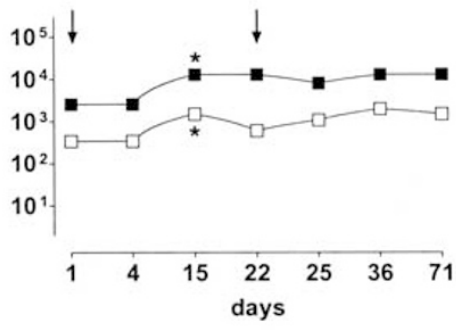

Patient 004

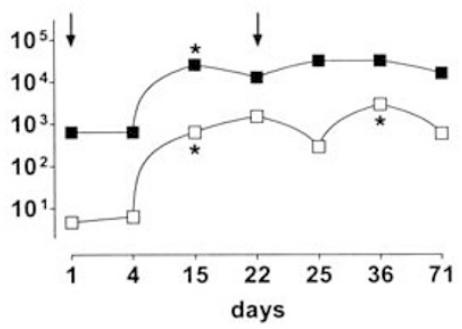

Patient 006

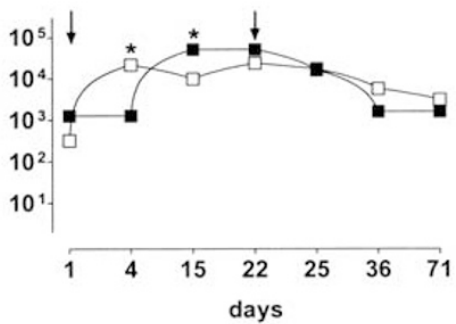

Figure 4 Anti-adenoviral ( $\square$ ) and neutralizing anti-adenoviral ( $\square$ ) Abs in patients before and after $r$ Ad/hup53 vaccination. An at least four-fold increase of the serum Ab titer as compared with the preceding Ab titer was considered to be significant (*). The days of $r$ Ad/hup53 delivery are indicated by arrows.

cination. In contrast to humoral immune responses specific for adenovirus encoded non-self gene products, such as $\beta$-galactosidase and suicide proteins, ${ }^{24,28,29}$ delivery of p53-recombinant viral vectors into mice ${ }^{4}$ and $\operatorname{man}^{30}$ did not induce $\mathrm{Ab}$ responses directed to the self-p53 protein.

$\mathrm{CD}^{+} \mathrm{T}$ helper (Th) cell responses specific for $\mathrm{p} 53$ peptides presented by class II MHC molecules are usually required to induce p53-reactive $\mathrm{Ab}$ production by $\mathrm{B}$ lymphocytes. Such p53 peptide-directed Th cells are believed to be resistant to p53-specific self-tolerance. ${ }^{31}$ Their presence has been demonstrated in patients with p53mutational tumors. ${ }^{31}$ We did not detect p53-reactive IFN$\gamma$-producing Th lymphocytes by comparing the frequencies of $\mathrm{CD}^{+} \mathrm{T}$ cells stimulated with autologous DCs that had been infected with either rAd/hup53 or rAd/empty. This experimental set-up, however, was biased towards the detection of adenoviral backbonereactive $\mathrm{T}$ cells. In one patient, stimulation of $\mathrm{CD} 4^{+} \mathrm{T}$ cells with autologous DCs pulsed with p53 protein confirmed the absence of p53-specific IFN- $\gamma$ producers.

Cross-talk between tumor-reactive CD8 ${ }^{+}$CTLs and Th lymphocytes, either directly or indirectly by cross-priming via activation of Ag-presenting DCs, has been considered key to the induction of potent CTL-based immune responses towards class II MHC-negative malig- nancies. ${ }^{32,33}$ Cross-priming by professional APCs and cognate Th cell recognition of peptides that are derived from a related, as opposed to an unrelated, tumor-associated protein has been demonstrated to be particularly effective in generating tumor-reactive CTLs specific for epitopes corresponding to the related tumor-associated $\mathrm{Ag}$ source. ${ }^{34}$ Considering that adenoviral backbonereactive Th lymphocyte responses were amplified by rAd/hup53 vaccination, a failure to simultaneously induce p53 transgene-specific Th cells may have thus contributed to the absence of p53-reactive $\mathrm{CD}^{+} \mathrm{T}$ cells responding to $\mathrm{A} 2.1$-presented wt p53 epitopes and, in one patient, to p53 protein-labeled DCs. Although the generation of CTLs specific for non-self $\beta$-galactosidase Ags by injection of a recombinant adenoviral vector has not been prevented by adenovirus-specific $\mathrm{Abs}^{28,29}$ we cannot necessarily preclude the possibility that the presence of neutralizing anti-adenoviral Abs in our study patients may have limited the induction of low- and residual high-avidity p53-specific CTLs. Another possibility that could explain the lack of p53-specific $\mathrm{T}$ cell responses in our patients results from the recent observation that adenoviral transduction of tumor cells leads to enhanced activation-induced cell death of tumorreactive $\mathrm{T}$ lympocytes, which can be partially reverted by 
Patient 001

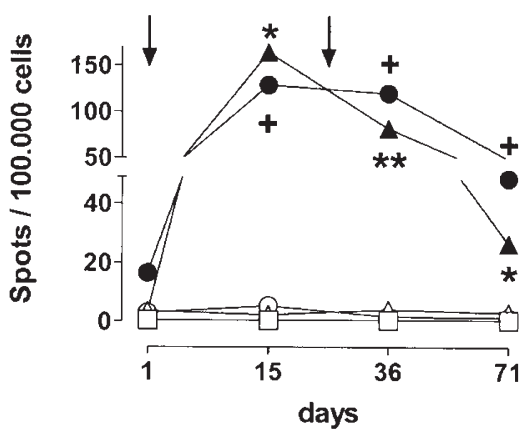

Patient 003

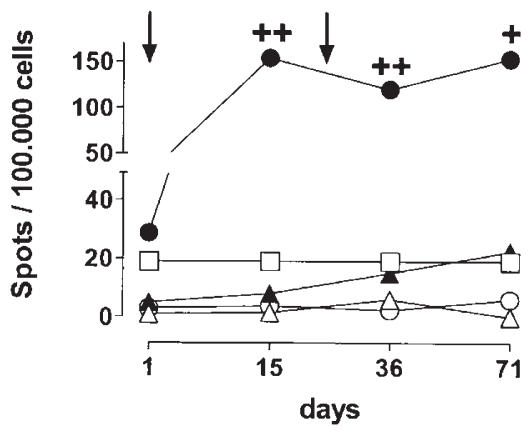

Patient 005

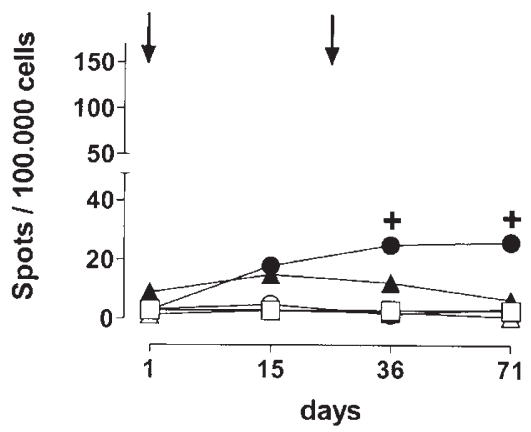

Patient 002

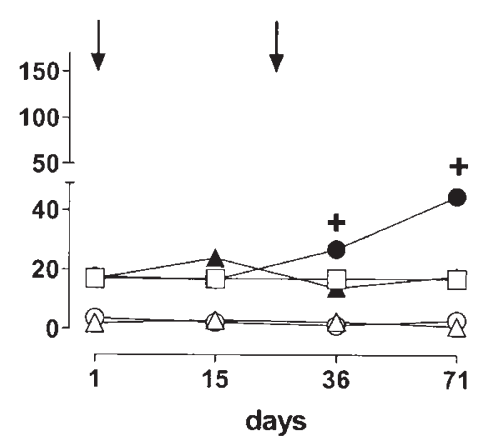

Patient 004

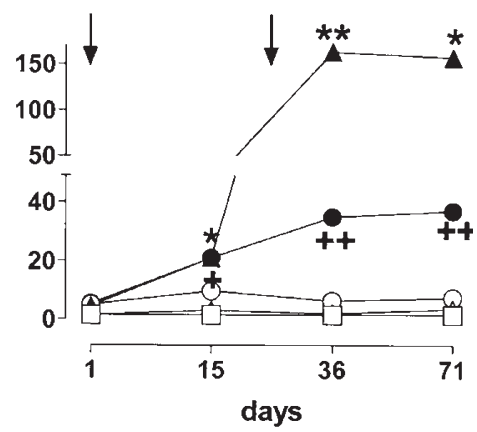

Patient 006

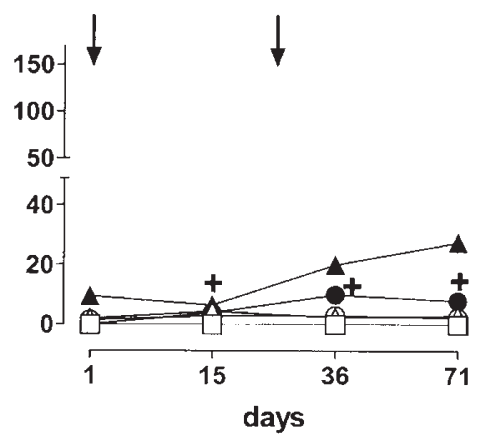

Figure 5 Adenoviral backbone-reactive and IFN- $\gamma$ secreting T lymphocyte subsets are induced by $r$ Ad/hup53 vaccination. The frequencies of peripheral blood-derived and adenovirus-reactive $C D 4^{+}$and $C D 8^{+} T$ cell subsets were determined by an IFN- $\gamma$ ELISPOT assay at an effector to stimulator cell ratio of 5:1. $C D 4^{+}(\mathbf{\bullet}, O)$, and $C D 8^{+}(\mathbf{\Lambda}, \triangle) T$ cells were stimulated by immature autologous DCs infected with either rAd/empty $(M O I$ 100) $(\bullet, \mathbf{\Delta})$ or MVA-hTyr (MOI 10) $(O, \triangle)$. Immature DC stimulators infected with rAd/empty and used without adding effector $T$ cells served as an additional negative control $(\square)$. The frequencies of IFN-y producing effector $T$ lymphocyte subsets are plotted as spots per $1 \times 10^{5} C D 4^{+}$or CD8 $8^{+} T$ cells. A statistically significant increase of $C D 4^{+}\left({ }^{+} P \leqslant 0.05,{ }^{+} P \leqslant 0.005\right)$ and $C D 8^{+}(* P \leqslant 0.05, * * P \leqslant 0.005) T$ cell frequencies was determined by Student's $t$ test for unpaired samples. The days of $r$ Ad/hup53 delivery are indicated by arrows.

CD80 and IL-7 gene transfer. ${ }^{35}$ Adenoviral gene expression by tumor cells upon vaccination may therefore cause increased deletion of tumor Ag-specific T cells.

Variable primary in vitro $\mathrm{T}$ cell responses to wt p53 have been reported in healthy donors and $\mathrm{p} 53^{-}$versus p53 ${ }^{+}$cancer patients. ${ }^{36,37}$ In contrast to A2.1-Tg mice, however, CTLs, if any, were of low avidity and target cell lyses were weak. ${ }^{36,37}$ We did not observe p53-specific CTLs in neither $3 / 6$ p53- nor in $3 / 6$ p53 $3^{+}$cancer patients. Consistent with our observation that tetramer staining and ELISPOT assays yield comparable frequencies of Agspecific $\mathrm{T}$ cells (WH and TW, unpublished), tetramer staining of $\mathrm{CD}^{+} \mathrm{T}$ lymphocytes from patient 002 on days
36 and 71 after $\mathrm{rAd} /$ hup53 vaccination confirmed the absence of wt p53.149-157 and 264-272-specific $\mathrm{T}$ cell responses (data not shown). We cannot preclude the possibility that extensive ex vivo restimulation of very low-frequent lymphocytes pre- and post-immunization would have yielded low-avidity anti-p53 CTLs. Such T cells, however, would have been of no clinical significance. We believe therefore that $\mathrm{rAd} /$ hup53-based vaccination of cancer patients is affected by both wt p53-specific tolerance and the presence and enhancement of antiadenovirus antibodies, which may inhibit virus entry and stimulation of anti-p53 immune responses.

We conclude that p53-based cancer immunotherapy is 
likely to require the interference with p53-specific selftolerance and the induction of the entire repertoire of p53-reactive $\mathrm{T}$ lymphocytes by $\mathrm{rAd} /$ hup53 transduced DC vaccination, ${ }^{36}$ concomitant expression of costimulatory molecules in tumor cells, ${ }^{35,38}$ or by p53-reactive $\mathrm{T}$ cell antigen receptor gene transfer ${ }^{39}$ or use of peptide variants. ${ }^{40}$

\section{Patients, materials and methods}

\section{Peptides}

Synthetic peptides used in the study were representative of hu wt p53 protein residues 149-157 (hu wt p53.149-157 STPPPGTRV), 187-197 (wt p53.187-197 GLAPPQHLIRV), 264-272 (hu wt p53.264-272 LLGRNSFEV), and 322-330 (wt p53.322-330 PLDGEYFTL). Only those p53 peptides that had been proven to function as naturally processed A2.1 ligands were chosen. Peptides p53.149-157, 187-197, and 264-272 are immunogeneic and represent natural epitopes that are endogenously processed and presented by p53-overexpressing tumor cells for recognition by A2.1restricted CTLs. ${ }^{2,5,6,8,11}$ The p53 peptides were either identical (homologous) (p53.187-197 and 322-330) or nonhomologous (p53.149-157 and 264-272) to mu wt p53 sequences. The A2.1-binding synthetic peptides GILGFVFTL, GLCTLVAML and ILKEPVHGV, corresponding to residues $58-66$ of the $\mathrm{A} / \mathrm{PR} / 8 / 34$ influenza matrix protein M1 (Flu M1 58-66), ${ }^{41}$ residues $280-288$ of the EBV protein BMLF-1 (EBV-B 280-288) ${ }^{42}$ and residues 476-484 of the reverse transcriptase of hu immunodeficiency virus type 1,43 respectively, served as controls. Purity of synthetic peptides was ascertained by reversed phase HPLC and mass spectrometry.

\section{Cell lines and transfectants}

Previously described cell lines and transfectants used in these studies included T2 cells, T2-A2.1/K $\mathrm{K}^{\mathrm{b}}\left(\mathrm{T} 2 \mathrm{~A} 2 \mathrm{~K}^{\mathrm{b}}\right)$, and Jurkat-A2.1 (JA2) transfectants, the $\mathrm{H}-2^{\mathrm{b} / \mathrm{b}}$ thymoma line EL4, the naturally A2.1-positive, p53-deficient osteosarcoma line Saos-2, and this same cell line transfected with a hu p53 gene harboring a mutation at residue 143 (V to A), Saos-2/143. ${ }^{15,44,45} \mathrm{~T} 2 \mathrm{~A} 2 \mathrm{~K}^{\mathrm{b}}$ and JA2 lines were a kind gift of LA Sherman (The Scripps Research Institute, La Jolla, CA, USA). Saos-2/143 p53 transfectants were kindly provided by AJ Levine (The Rockefeller University, New York, NY, USA).

\section{Mice}

The derivation of $\mathrm{A} 2 \mathrm{~K}^{\mathrm{b}}$ line 6 and $\mathrm{p} 53^{-/-} \mathrm{A} 2 \mathrm{~K}^{\mathrm{b}-/+}-\mathrm{Tg}$ mice (p53 $3^{-1-} \mathrm{A} 2 \mathrm{~K}^{\mathrm{b}}-\mathrm{Tg}$ ) has been described. ${ }^{6,16} \mathrm{C} 57 \mathrm{BL} / 6$ mice were crossed with $A 2 K^{b}$ line $6 \mathrm{Tg}$ mice to obtain $\mathrm{p}^{2} 3^{+/+} \mathrm{A} 2 \mathrm{~K}^{\mathrm{b}-/+}$ mice (p53 $3^{+/+} \mathrm{A} 2 \mathrm{~K}^{\mathrm{b}}-\mathrm{Tg}$ mice). A2 $\mathrm{K}^{\mathrm{b}}$ line 6 and $\mathrm{p} 53^{-/-} \mathrm{A} 2 \mathrm{~K}^{\mathrm{b}}-\mathrm{Tg}$ mice were kindly provided by LA Sherman. C57BL/ 6 mice were purchased from the breeding colony of the Johannes Gutenberg-University (JGU). Mice were propagated and maintained at the animal facility of JGU. All experimental procedures were performed according to the National Institutes of Health Guide for the Care and Use of Laboratory Animals.

\section{Priming $p 53^{-1-}$ and $p 53^{+/+} A 2 K^{b}-T g$ mice and propagation of CTLS}

Mice were immunized i.p. with rAd/hup53 or $\mathrm{rAd} /$ empty at $1 \times 10^{11}$ particles in a volume of $0.5 \mathrm{ml}$
PBS. As indicated, mice were injected s.c. at the base of the tail with $100 \mu \mathrm{g}$ of either two (p53.149-157 and p53.264-272) or three (p53.149-157, p53.264-272 and p53.187-197) synthetic wt p53 peptides and 200 to $300 \mu \mathrm{g}$ of an $\mathrm{I}-\mathrm{A}^{\mathrm{b}}$-binding synthetic $\mathrm{T}$ helper peptide representing residues $128-140$ of the hepatitis $B$ virus core protein $^{46}$ emulsified in $150 \mu$ l of incomplete Freunds adjuvant. $^{2}$ After 10 days (peptide immunization) or 3 weeks (virus inoculation), spleen cells of primed mice were cultured with irradiated $\mathrm{A} 2 \mathrm{~K}^{\mathrm{b}}-\mathrm{Tg}$ lipopolysaccharide (LPS) activated spleen cell stimulators that had been pulsed with either p53.149-157, 187-197, or 264-272 peptides at $5 \mu \mathrm{g} / \mathrm{ml}$, and hu $\beta_{2}$-microglobulin at $10 \mu \mathrm{g} / \mathrm{ml}$ in complete RPMI medium (RPMI 1640 containing 10\% (vol/vol) fetal calf serum, $25 \mathrm{mM}$ Hepes, $2 \mathrm{mM}$ glutamine, $5 \times 10^{-5} \mathrm{M} \beta$-mercaptoethanol, and $50 \mu \mathrm{g} / \mathrm{ml}$ gentamycin). ${ }^{2}$ After 6 days, the resultant effector cells were assayed in a 5 -h ${ }^{51} \mathrm{Cr}$-release assay ${ }^{15}$ at various effector/target (E:T) ratios for lytic activity in response to Saos- 2 and Saos-2/143 cells, and T2A2K ${ }^{\mathrm{b}}$ or EL4 targets that had been pulsed with either no peptide, stimulating wt p53 peptides, or FluM1 58-66 control peptide at the indicated concentrations. Immunization of $\mathrm{p} 53^{-/-}$ and $\mathrm{p} 53^{+/+} \mathrm{A} 2 \mathrm{~K}^{\mathrm{b}}-\mathrm{Tg}$ mice with $\mathrm{rAd} /$ hup53 and $\mathrm{rAd} / \mathrm{empty}$, as well as subsequent effector cell cultures and ${ }^{51} \mathrm{Cr}$-release assays were performed simultaneously. A polyclonal, A2.1-restricted CTL line (CTL A2K ${ }^{\mathrm{b}}$ 187) derived from $\mathrm{rAd} /$ hup53-primed $\mathrm{p} 53^{-/-} \mathrm{A} 2 \mathrm{~K}^{\mathrm{b}}-\mathrm{Tg}$ mice and specific for p53.187-197 was established by weekly restimulation of effector CTLs with irradiated JA2 stimulators that had been pulsed with $5 \mu \mathrm{g}$ of the p53 peptide, irradiated C57BL/6 spleen filler cells, and 2-10\% (vol/vol) of rat concanavalin A supernatant. ${ }^{15}$

\section{CTL lines and clones}

An A2.1-restricted CTL clone specific for hu wt p53.264272 (CTL A2 $264 \mathrm{cl}$ 46) was established by limiting dilution of a polyclonal CTL line (CTL A2 264) derived from an A2.1-Tg mouse. ${ }^{2}$ The derivation and maintenance of an A2.1-restricted CTL line specific for the FluM1 58-66 peptide (CTL CD8 $\times$ A2 $\mathrm{K}^{\mathrm{b}}$ FluM1) has been described previously. ${ }^{47}$ An allo-reactive A2.1-specific polyclonal CTL line (CTL CD8 Allo A2) was established as reported. ${ }^{2}$ Clonal and polyclonal CTLs were used as effector cells at the indicated E:T ratios in ${ }^{51} \mathrm{Cr}$-release assays.

\section{Patients}

Six patients suffering from advanced-stage cancer were enrolled in a pilot study evaluating the safety, feasibility and efficacy of vaccination with $\mathrm{rAd} /$ hup53. Evidence for p53 mutation in tumor tissue samples was required in three of six patients and was determined by immunohistochemistry. ${ }^{48}$ Patients had to be A2-positive as tested by HLA-serotyping. Additional HLA-genotyping revealed that one of the six patients who had eventually been enrolled in the study expressed HLA-A*0205 as opposed to the A2.1-allele. Patients were required to be at least 18 years old. Eligible patients were those with a life expectancy of at least 3 months, a Karnofsky score of at least $70 \%$, acceptable renal and liver function, and acceptable peripheral blood cell counts. Chemotherapy, radiation, or major surgery were not allowed within 4 weeks before treatment. Systemic corticoid or other immunosuppressive therapy was not permitted within the last 3 months. 
Pregnant women, patients with uncontrolled serious bacterial, fungal, parasitic, or viral infections, or anamnestic, clinical, or laboratory evidence for autoimmune disease, or allergic diathesis were not eligible. Six out of a total of 50 screened patients eventually met the eligibility criteria and were enrolled in the study between December 1998 and July 1999 (Table 1).

\section{Study medication}

rAd/hup53 (SCH58500) has been used in several phase I-III clinical trials in which transgene expression has been demonstrated. ${ }^{48}$ SCH58500 is an aqueous solution of a replication-deficient recombinant adenovirus type 5 containing the complete hu wt p53 cDNA under the control of the hu cytomegalovirus immediate-early gene promoter. ${ }^{49}$ SCH58500 was provided by the Schering-Plough Research Institute (Kenilworth, NJ, USA) and Canji Incorporation (San Diego, CA, USA).

\section{Study design and treatment}

The study was an open-label, single-arm design and was conducted at a single center (JGU). Blood samples were drawn pretreatment (day 0 or day 1) and on days 15, 36 and 71 for isolation and cryopreservation of PBMCs. Patients received two i.d. and two s.c. injections of a total volume of $1 \mathrm{ml}$ of $\mathrm{rAd} /$ hup53 at $7.5 \times 10^{11}$ particles $/ \mathrm{ml}$ at a femoral site on days 1 and 22. Clinical tumor responses were assessed on day 71 by imaging diagnostics using National Cancer Institute response criteria. All patients provided written informed consent. The protocol was approved by the institutional review board (EthikKommission der Landesärztekammer Rheinland-Pfalz), the national regulatory agency (Kommission Somatische Gentherapie der Bundesärztekammer), and the study was conducted in compliance with the Declaration of Helsinki and Good Clinical Practice guidelines.

\section{Study objectives}

Primary aim of the study was to evaluate safety, feasibility and efficacy of rAd/hup53 vaccination in patients with advanced-stage cancer. Secondary endpoint of the trial was the assessment of humoral and cellular immune responses to adenoviral backbone- and p53-derived Ags following rAd/hup53 vaccination.

\section{Detection of anti-adenovirus Abs}

The presence of anti-adenovirus Abs was measured in serum obtained from rAd/hup53 vaccinated patients by an enzyme-linked immunosorbent assay as described previously. ${ }^{48}$ Neutralizing anti-adenoviral Abs were determined in a fluorescent $\mathrm{Ab}$-based biological assay (LW, unpublished).

\section{Anti-p53 Ab assay}

Real-time biospecific interaction analysis ${ }^{50}$ was utilized to detect the presence of Abs directed against p53 protein in serum collected from $\mathrm{rAd} /$ hup53-vaccinated patients. Synthetic peptides corresponding to amino acids 11-35, $40-65$, and 371-390 of the wt p53 protein were immobilized on to the surface of a CM5 research grade biosensor chip by either amine or thiol coupling chemistry using a BIACORE 2000 device (Pharmacia Biosensor, Uppsala, Sweden). Serum obtained from a pool of healthy individuals and a sheep polyclonal anti-p53 Ab (Oncogene Sciences, Uniondale, NY, USA) served as negative and positive controls, respectively. The diluted experimental

and control samples were sequentially injected on to the immobilized peptide surfaces and monitored for binding as indicated by an increase in response units as compared with baseline values generated at the start of each injection. Control samples were tested throughout the assay to ensure that the level of binding remained stable during the assay.

\section{$D C s$}

To generate hu monocyte-derived autologous DCs, PBMCs were isolated by Ficoll density centrifugation and washed five times in phosphate buffered saline (PBS; BioWhittaker, Germany) to remove platelets. Cells were resuspended in serum-free X-Vivo 15 (BioWhittaker) at 1 $\times 10^{6} / \mathrm{ml}$, seeded for $1 \mathrm{~h}$ at $37^{\circ} \mathrm{C}\left(5 \% \mathrm{CO}_{2}\right)$ in tissue culture flasks (Costar, Corning, NY, USA), and washed with PBS to remove non-adherent cells. Non-adherent cells were stored in liquid nitrogen. Adherent cells were cultured in serum-free X-Vivo 15 containing rhIL-4 at 1000 $\mathrm{U} / \mathrm{ml}$ and rhGM-CSF at $1000 \mathrm{U} / \mathrm{ml}$ (Schering-Plough). On days 3 and $5,3 \mathrm{ml}$ of fresh medium supplemented with rhIL-4 at $1000 \mathrm{U} / \mathrm{ml}$ and rhGM-CSF at $1600 \mathrm{U} / \mathrm{ml}$ was added. On day 7, immature DCs were collected and stored in liquid nitrogen. Immature DCs served as targets in the IFN- $\gamma$-ELISPOT assay. To induce maturation of DCs, immature DCs were seeded in serum-free X-Vivo 15 in six-well plates (Costar, Corning) at $1 \times 10^{6}$ cells per well, and the following cytokines were added for 2 days: rhIL- 4 at $500 \mathrm{U} / \mathrm{ml}$, rhGM-CSF at $800 \mathrm{U} / \mathrm{ml}$, rhIL-1 at $10 \mathrm{ng} / \mathrm{ml}$ (Genzyme, Konstanz, Germany), rhIL-6 at 1000 $\mathrm{U} / \mathrm{ml}$ (Novartis, Basel, Switzerland), TNF- $\alpha$ at $10 \mathrm{ng} / \mathrm{ml}$ (Sigma, Taufkirchen, Germany), and prostaglandin $\mathrm{E}_{2}$ at $1 \mu \mathrm{g} / \mathrm{ml}$ (Sigma). Mature DCs were used as targets in ${ }^{51} \mathrm{Cr}$-release assays. Immature DCs $\left(1 \times 10^{6}\right)$ were infected in $\mathrm{PBS}$ at $37^{\circ} \mathrm{C}\left(5 \% \mathrm{CO}_{2}\right)$ for $45 \mathrm{~min}$ with $\mathrm{rAd} /$ hup53 or $\mathrm{rAd} / \mathrm{empty}^{51}$ or with a recombinant modified vaccinia virus Ankara encoding for hu tyrosinase (MVA-hTyr) ${ }^{47}$ at the indicated multiplicity of infection (MOI). Infected cells were cultured in serum-free X-Vivo 15 for $48 \mathrm{~h}$ in the presence of cytokines used for the induction of DCs. MVA-hTyr was kindly provided by I Drexler (Technical University Munich, Germany).

\section{Frequency estimation of adenoviral backbone- and wt p53-specific $C D 4^{+}$and $C D 8^{+} T$ lymphocytes}

The frequency of adenoviral backbone- and hu wt p53specific IFN- $\gamma$-secreting peripheral blood $\mathrm{CD}^{+}$and $\mathrm{CD}^{+}$ $\mathrm{T}$ cells was determined by an IFN- $\gamma$-ELISPOT assay that takes advantage of anti-hu IFN- $\gamma$-capture (1-D1-K) and detection (7-B6-1) monoclonal Abs (Mabtech, Stockholm, Sweden). ${ }^{52}$ The number of spots was determined by an automated and computer-assisted video-image analyser (Zeiss-Kontron, Jena, Germany). Briefly, the fraction of non-adherent PBMCs was thawed and CD4 ${ }^{+}$and $\mathrm{CD}^{+}$ $\mathrm{T}$ lymphocytes were positively selected by MicroBeads (Miltenyi Biotec, Bergisch Gladbach, Germany) according to the manufacturer's advice. Selected T cells were cocultered under serum-free conditions at $1 \times 10^{5} /$ well with autologous immature DCs at an effector to stimulator ratio of 5:1. Ag specificity of selected T cells was evaluated by adding p53 or control peptides at a final concentration of $10^{-4}$ to $10^{-5} \mathrm{M}$, p53 or E7 protein at $10 \mu \mathrm{g} / \mathrm{ml}$ (kindly provided by KLMC Franken, University Hospital Leiden, The Netherlands), and by using autologous 
immature DCs that had been infected or non-infected with either rAd/empty, rAd/hup53, or MVA-hTyr. Nonpeptide-pulsed and phytohemagglutinin (2 $\mu \mathrm{g} / \mathrm{ml})$ (Sigma) supplemented cocultures served as additional negative and positive controls, respectively. The frequency of Ag-specific $\mathrm{T}$ cell subsets was estimated according to the mean number of spots detected following Ag-specific versus background stimulation.

\section{Acknowledgements}

We thank the patients and their families for participating in this trial. We gratefully acknowledge the contributions of P Meinhardt, F Schmitz, H Huberts, JA Horowitz, B Hutchins and D Maneval. We thank M Jülch for flow cytometry analyses and C Lotz for critically reading the manuscript. These studies were supported by a grant from the Schering-Plough Research Institute, by the Tumor Vaccination Center at JGU (funded by the Deutsche Krebshilfe eV), and by grants from the Deutsche Forschungsgemeinschaft (SFB 432 A3) and the Stiftung Rheinland-Pfalz für Innovation to MT, and the MAIFOR program to JK and MT.

\section{References}

1 Levine AJ. p53, the cellular gatekeeper for growth and division. Cell 1997; 88: 323-331.

2 Theobald $\mathrm{M}$ et al. Targeting p53 as a general tumor antigen. Proc Natl Acad Sci USA 1995; 92: 11993-11997.

3 Mayordomo JI et al. Therapy of murine tumors with p53 wildtype and mutant sequence peptide-based vaccines. J Exp Med 1996; 183: 1357-1365.

4 Roth J et al. p53 as a target for cancer vaccines: recombinant canarypox virus vectors expressing p53 protect mice against lethal tumor challenge. Proc Natl Acad Sci USA 1996; 93: 47814786.

5 Röpke $\mathrm{M}$ et al. Spontaneous human squamous cell carcinomas are killed by a human cytotoxic T lymphocyte clone recognizing a wild-type p53 derived peptide. Proc Natl Acad Sci USA 1996; 93: 14704-14707.

6 Theobald $\mathrm{M}$ et al. Tolerance to p53 by A2.1-restricted cytotoxic T lymphocytes. J Exp Med 1997; 185: 833-841.

7 Vierboom MP et al. Tumor eradication by wild-type p53-specific cytotoxic T lymphocytes. J Exp Med 1997; 186: 695-704.

$8 \mathrm{Yu} \mathrm{Z}$ et al. The use of transgenic mice to generate high affinity p53 specific cytolytic T cells. J Surg Res 1997; 69: 337-343.

9 Gnjatic $S$ et al. Accumulation of the p53 protein allows recognition by human CTL of a wild-type p53 epitope presented by breast carcinomas and melanomas. J Immunol 1998; 160: 328-333.

10 Theobald $\mathrm{M}$ et al. The sequence alteration associated with a mutational hotspot in $\mathrm{p} 53$ protects cells from lysis by cytotoxic T lymphocytes specific for a flanking peptide epitope. J Exp Med 1998; 6: 1017-1028.

11 Chikamatsu $\mathrm{K}$ et al. Generation of anti-p53 cytotoxic T lymphocytes from human peripheral blood using autologous dendritic cells. Clin Cancer Res 1999; 5: 1281-1288.

12 Vierboom MP et al. High steady-state levels of p53 are not a prerequisite for tumor eradication by wild-type p53-specific cytotoxic T lymphocytes. Cancer Res 2000; 60: 5508-5513.

13 Houbiers JG et al. In vitro induction of human cytotoxic T lymphocyte responses against peptides of mutant and wild-type p53. Eur J Immunol 1993; 23: 2072-2077.

14 Ishida $\mathrm{T}$ et al. Dendritic cells transduced with wild-type p53 gene elicit potent anti-tumor responses. Clin Exp Immunol 1999; 117: 244-251.

15 Irwin MJ, Heath WR, Sherman LA. Species-restricted interactions between CD 8 and the $\alpha 3$ domain of class I influence the magnitude of xenogeneic response. J Exp Med 1989; 170: 10911101

16 Vitiello A et al. Analysis of the HLA-restricted influenza-specific cytotoxic $\mathrm{T}$ lymphocyte response in transgenic mice carrying a chimeric human-mouse class I major histocompatibility complex. J Exp Med 1991; 173: 1007-1015.

17 Schirle $\mathrm{M}$ et al. Identification of tumor-associated MHC class I ligands by a novel $\mathrm{T}$ cell-independent approach. Eur J Immunol 2000; 30: 2216-2225.

18 Flomenberg P, Piaskowski V, Truitt RL, Casper JT. Characterization of human proliferative $\mathrm{T}$ cell responses to adenovirus. $J$ Infect Dis 1995; 171: 1090-1096.

19 Liu GY et al. Low avidity recognition of self-antigen by T cells permits escape from central tolerance. Immunity 1995; 3: 407415.

20 Nijman HW et al. Charcaterization of cytotoxic T lymphocyte epitopes of a self-protein, p53, and a non-self-protein, influenza matrix: Relationship between major histocompability complex peptide binding affinity and immune responsiveness to peptides. J Immunother 1993; 14: 121-126.

21 Karjalainen K. High sensitivity, low affinity-paradox of T-cell receptor recognition. Curr Opin Immunol 1994; 6: 9-12.

22 Alexander-Miller MA, Leggatt GR, Sarin A, Berzofsky JA. Role of antigen, CD8, and cytotoxic T lymphocyte (CTL) avidity in high dose antigen induction of apoptosis of effector CTL. J Exp Med 1996; 184: 485-492.

23 Chen W, Antón LC, Bennink JR, Yewdell JW. Dissecting the multifactorial causes of immunodominance in class I restricted T cell responses to viruses. Immunity 2000; 12: 83-93.

24 Molnar-Kimber KL et al. Impact of pre-existing and induced humoral and cellular immune responses in an adenovirus-based gene therapy phase I clinical trial for localized mesothelioma. Hum Gene Ther 1998; 9: 2121-2133.

25 Harvey BG et al. Variability of human systemic humoral immune response to adenovirus gene transfer vectors administered to different organs. J Virol 1999; 73: 6729-6742.

26 Kafri $\mathrm{T}$ et al. Cellular immune responses to adenoviral vector infected cells does not require de novo viral gene expression: implications for gene therapy. Proc Natl Acad Sci USA 1998; 95: 11377-11382.

27 Soussi T. p53 antibodies in the sera of patients with various types of cancer: a review. Cancer Res 2000; 60: 1777-1788.

28 Gahéry-Ségard $\mathrm{H}$ et al. Phase I trial of recombinant adenovirus gene transfer in lung cancer. J Clin Invest 1997; 100: 2218-2226.

29 Molinier-Frenkel V et al. Longitudinal follow-up of cellular and humoral immunity induced by recombinant adenovirusmediated gene therapy in cancer patients. Hum Gene Ther 2000; 11: 1911-1920.

30 Yen $\mathrm{N}$ et al. Cellular and humoral immune response to adenovirus and p53 protein antigens in patients following intratumoral injection of an adenovirus vector expressing wild-type p53 (Ad-p53). Cancer Gene Ther 2000; 7: 530-536.

31 Van der Burg $\mathrm{SH}$ et al. Long lasting p53-specific T cell memory responses in the absence of anti-p53 antibodies in patients with resected primary colorectal cancer. Eur J Immunol 2001; 31: 146-155.

32 Bennett SR et al. Help for cytotoxic-T-cell responses is mediated by CD40 signalling. Nature 1998; 393: 478-480.

33 Schoenberger SP et al. T-cell help for cytotoxic T lymphocytes is mediated by CD40-CD40L interactions. Nature 1998; 393: 480-483.

34 Ossendorp $\mathrm{F}$ et al. Specific T helper cell requirement for optimal induction of cytotoxic T lymphocytes against major histocompatibility complex class II negative tumors. J Exp Med 1998; 187: 693-702.

35 Scholz $\mathrm{C}$ et al. Adenoviral transduction of tumor cells induces apoptosis in co-cultured T-lymphocytes (submitted for publication).

36 Nikitina EY et al. Dendritic cells transduced with full-length p53 generate antitumor cytotoxic $\mathrm{T}$ lymphocytes from peripheral blood of cancer patients. Clin Cancer Res 2001; 7: 127-135. 
37 Hoffmann TK et al. Generation of T cells specific for the wildtype sequence $\mathrm{p} 53_{264-272}$ peptide in cancer patients: implications for immunoselection of epitope loss variants. I Immunol 2000; 165: 5938-5944.

38 Daniel PT et al. Costimulatory signals through B7.1/CD28 prevent $\mathrm{T}$ cell apoptosis during target cell lysis. J Immunol 1997; 159: 3808-3815.

39 Stanislawski $\mathrm{T}$ et al. Circumventing tolerance to a human MDM2-derived tumor antigen by TCR gene transfer. Nat Immunol 2001; 2: 962-970.

40 Hoffmann TK et al. The ability of variant peptides to reverse the nonresponsiveness of $\mathrm{T}$ lymphocytes to the wild-type sequence p53 $264-272$ epitope. J Immunol 2002; 168: 1338-1347.

41 Morrison $\mathrm{J}$ et al. Identification of the nonamer peptide from influenza A matrix protein and the role of pockets of HLA-A2 in its recognition by cytotoxic T lymphocytes. Eur J Immunol 1992; 22: 903-907.

42 Steven NM et al. Immediate early and early lytic cycle proteins are frequent targets of the Epstein-Barr virus-induced cytotoxic T cell response. J Exp Med 1997; 185: 1605-1618.

43 Tsomides TJ, Walker BD, Eisen HN. An optimal viral peptide recognized by $\mathrm{CD} 8^{+} \mathrm{T}$ cells binds very tightly to the restricting class I major histocompatibility complex protein on intact cells but not to the purified class I protein. Proc Natl Acad Sci USA 1991; 88: 11276-11280.

44 DeMars $\mathrm{R}$ et al. Mutations that impair a posttranscriptional step in expression of HLA-A and -B antigens. Proc Natl Acad Sci USA 1985; 82: 8183-8187.

45 Dittmer D et al. Gain of function mutations in p53. Nat Genet 1993; 4: 42-46.

46 Sette A et al. The relationship between class I binding affinity and immunogenicity of potential cytotoxic $\mathrm{T}$ cell epitopes. $J$ Immunol 1994; 153: 5586-5592.

47 Drexler I et al. Modified vaccinia virus Ankara for delivery of human tyrosinase as melanoma-associated antigen: Induction of tyrosinase- and melanoma-specific human leukocyte antigen A*0201-restricted cytotoxic T cells in vitro and in vivo. Cancer Res 1999; 59: 4955-4963.

48 Schuler $\mathrm{M}$ et al. A phase I study of adenovirus mediated gene transfer in patients with advanced non-small cell lung cancer. Hum Gene Ther 1998; 14: 2075-2082.

49 Wills KN et al. Development and characterization of recombinant adenoviruses encoding human p53 for gene therapy of cancer. Hum Gene Ther 1994; 5: 1079-1088.

50 Johnsson B, Lofas S, Lindquist G. Immobilization of proteins to a carboxymethyldextran modified gold surface for biospecific interaction analysis in surface plasmon resonance. Anal Biochem 1991; 198: 268-277.

51 Ranieri E et al. Dendritic cells transduced with an adenovirus vector encoding Epstein-Barr virus latent membrane protein 2B: a new modality for vaccination. J Virol 1999; 73: 10416-10425.

52 Wölfel C et al. Transporter (TAP)- and proteasome-independent presentation of a melanoma-associated tyrosinase epitope. Int J Cancer 2000; 88: 432-438.

53 Miller AB, Hoogstraten B, Staquet M, Winkler A. Reporting results of cancer treatments. Cancer 1981; 47: 210-214. 